\title{
Evaluation of thyroid volume in patients with systemic sclerosis; what did we find?
}

\author{
Suade BADAK ${ }^{1}$, Bozkurt GÜLEK ${ }^{2}$, Esra KAYACAN ERDOĞGN² ${ }^{2}$ Hülya BINOKAY ${ }^{3}$, \\ and Eren ERKEN ${ }^{4}$
}

\author{
${ }^{1}$ Affiliation not available \\ ${ }^{2}$ Adana City Training and Research Hospital \\ ${ }^{3}$ Çukurova Universitesi \\ ${ }^{4}$ Acibadem Hospitals Group
}

April 28, 2021

\begin{abstract}
Introduction: Systemic sclerosis is a multisystemic disease. Thyroid involvement in systemic sclerosis is an issue that can be ignored. Our study aimed to evaluate the decreased thyroid volume in SSc. Also, we aimed to show the relationship between patients' thyroid volume and severity score, clinical and laboratory parameters. Method: This was a single-center, cross-sectional study. Eighty-eight patients were included in the study. A radiologist evaluated patients' thyroid volumes by ultrasonography. Demographic and clinical characteristics of the patients were recorded. Skin thickness was evaluated by the modified Rodnan skin score and the disease severity by the Medsger severity score. Findings were analyzed statistically. Results: Thyroid volume was in the atrophic range in $53.4 \%$ of the patients. There was a significant negative correlation between thyroid volume and mRSS, MSS, and disease duration. Logistic regression analysis showed that modified Rodnan skin score and disease duration were risk factors for thyroid atrophy. Conclusions: Many studies point out that thyroid autoantibodies are a cause of thyroid dysfunction in patients with SSc. However, in most of these studies, thyroid volume was not evaluated. As a result of our study, we saw that the major cause of thyroid dysfunction in our SSc patients was thyroid atrophy. Also, we observed that thyroid atrophy was more common in patients with ILD. We would like to draw attention to the fact that thyroid dysfunction and volume changes increase with the disease's duration and severity in systemic sclerosis.
\end{abstract}

\section{Hosted file}

thyroid_volume_what' new.pdf available at https://authorea.com/users/410683/articles/519969evaluation-of-thyroid-volume-in-patients-with-systemic-sclerosis-what-did-we-find

\section{Hosted file}

Table_endoc (1).edited (1).pdf available at https://authorea.com/users/410683/articles/ 519969-evaluation-of-thyroid-volume-in-patients-with-systemic-sclerosis-what-did-we-find 